\title{
Insights from a Latent Semantic Analysis of Patterns in Design Expertise: Implications for Education
}

\author{
Hernan Casakin $1, *(1)$ and Vishal Singh ${ }^{2}(\mathbb{D}$ \\ 1 School of Architecture, Ariel University, Ariel 44837, Israel \\ 2 Department of Civil Engineering, Aalto University, 02150 Otaniemi Espoo, Finland \\ * Correspondence: casakin@ariel.ac.il; Tel.: +972-508167756
}

Received: 28 June 2019; Accepted: 2 August 2019; Published: 5 August 2019

\begin{abstract}
Design and design thinking are increasingly being taught across several disciplines—ranging from arts, architecture, and technology and engineering to business schools-where expertise plays a central role. A substantial corpus of literature on research in regard to design expert and design expertise has accumulated in the last decades. However, in spite of its importance for design and design education, the topic has remained largely unframed. A major goal of this study was to carry out an assessment of literature through leading interdisciplinary design journals in order to identify main topics and categorize them into thematic patterns concerned with expertise in design. A structured assessment approach based on Latent Semantic Analysis (LSA) was used over 861 abstracts. The emerging thematic patterns associated with design expertise allowed a categorization at different levels of detail, which included 80, 50, 20, and 12 factors analyses, respectively. The major contribution of the study was to offer a structured assessment of key design literature that enabled to gain a clearer and more comprehensive understanding of the thematic patterns in the discussion on design expertise. Implications of the identified key factors for design education are discussed.
\end{abstract}

Keywords: expertise; design expert; design expertise; thematic pattern; latent semantic analysis; design education

\section{Introduction}

Design plays a central role in a broad spectrum of disciplines, ranging from arts and architecture, to technology and engineering, and business studies. Accordingly, disciplines view design from different perspectives, what includes subjective and social aspects in the arts, to more objective and scientific issues in the engineering disciplines. In spite of such differences, a common interest among these disciplines has been the study of design expertise. What expertise is [1], and what the features of a design expert are [2], continue to be a major topic of research interest in design. Bearing in mind the importance that these notions have for the development of design, and for design education in particular, e.g., [3], a comprehensive understanding of the emergent patterns and trends in interdisciplinary design literature is necessary, mainly considering the increasing demand for interdisciplinary approaches in design. It is therefore expected that a literature assessment will help to unveil some of the key factors that characterize design expertise, and facilitate its development and acquisition. In spite of the relevance that expertise has for design education, the subject has remained largely unframed.

Expertise is a human attribute that is closely associated with performance, quality, and productivity. This notion can be defined as a superior performance in a certain domain [4], and is based on knowledge, skills, and experience [5,6]. Expertise has been studied for more than 50 years across varied domains, and from different perspectives, including design. Given the broad significance of expertise in the design domain, there is a large body of existing literature that makes its review an ambitious 
task, especially as a comprehensive manual process. Typically, manual literature review involves a pre-selection of key articles that is often based on search criteria such as the number of citations of an article. This type of review approach, while insightful and quite common, is prone to be subjective and limiting in terms of the number of articles that can be covered. The potential tendency to focus on the more cited and influential papers might develop into a bias towards representative literature. In this study, we distinguish between critical review and the review of thematic patterns in the distribution and occurrence of the dominant themes in literature. Thus, instead of conducting a subjective evaluation regarding which themes are more important than others, a major goal of the present study is to use a semantic text analysis approach to carry out a quantitative and objective assessment to identify how the dominant themes appear across the corpus of assessed design literature. We would like to understand the main trends and topics associated with design expertise, and whether and how these can be organized and categorized into main thematic patterns. Eventually, understanding what topics relate to what kind of patterns, and at what level of detail may enable to gain a deeper understanding of what constitutes design expertise. A semantic analysis of existing literature can also provide further hints about what are the important issues that design students, educators, and practitioners should be aware of in regard to the development of expertise.

The frequency and occurrence of themes will be assessed through semantic grouping of the keywords using techniques such as Latent Semantic Analysis (LSA), which is a text data mining and natural language processing (NLP) technique [7]. Such methods are well established as valid and useful for identifying and understanding thematic patterns in literature, e.g., [8,9]. LSA allows a systematic, computational, and comprehensive analysis of a large corpus of literature for matching between query and document at topic level. In previous studies it was also showed that performing LSA over abstracts is adequate and suitable to identify the thematic patterns, since abstracts tend to provide the key summary of a paper and key terms, e.g., [10-12].

Therefore, by systematically applying LSA techniques to 861 paper abstracts selected from leading interdisciplinary design journals, this research presents a structured representation of key thematic patterns that have emerged in design expertise research over the last 25 years. The identified patters are of importance for intervention programs aimed to promote the acquisition and development of design expertise, for example in the design studio.

\section{Expertise in Design}

Expertise has been investigated extensively in the design domain, and it continues to be a major research topic (for an overview see Cross [13], and for special issues see Design Studies [14], and the Journal of Design Research [15]). Most design literature centers on questions about what are the competencies and skills that are necessary to be considered a design expert, and how an expert behaves during the design process. Design is characterized by extremely demanding standards set by the experts themselves [13]. Whereas literature on design expertise is vast, and a complete analysis and discussion of the topic is beyond the scope of this study, in this section we attempted to organize recurrent themes identified in relevant related studies (see Table 1).

Expertise is concerned with the designer ability to put into practice some level of superior competency. The nature of design ability can be defined by certain modes of behaving and thinking that designers express while tackling design problems. Cross [3] suggested core features of expert design competencies that conforms main design abilities. He identified eight abilities that included: solve ill-design problems, adopt solution-oriented approaches, produce novel and unexpected solutions, tolerate uncertainty when working with incomplete information, apply imagination to deal with practical problems, employ abductive and productive thinking, use non-verbal, use graphic/spatial modeling as a media of representation, and employ drawings and sketches as a means of problem solving. 
Table 1. Categories and themes identified in the design expertise literature.

\begin{tabular}{c}
\hline Domain Knowledge \\
\hline $\begin{array}{c}\text { Domain-specific knowledge; procedural knowledge; procedural skills; procedural actions; procedural } \\
\text { know-how; declarative knowledge; representational knowledge; conceptual knowledge; body of knowledge; } \\
\text { discipline knowledge; tacit knowledge; implicit knowledge; domain-specific knowledge; experiential } \\
\text { knowledge; technical knowledge; multi-disciplinary knowledge; knowledge structures; knowledge integration; } \\
\text { consistent knowledge }\end{array}$ \\
\hline Knowledge Strategies \\
\hline $\begin{array}{c}\text { Strategic knowledge/strategy; heuristics; rules of thumb; trial and error; solution oriented strategies; problem } \\
\text { oriented strategies; procedures; goals/sub-goals/limited strategy; trial and error; breadth first approach; } \\
\text { depth-first approach; top-down/bottom-up; deductive reasoning/approach }\end{array}$ \\
\hline
\end{tabular}

\section{Knowledge Representation}

Problem representation; mental representation; external representation; chunks of information; knowledge structure; encoding; visual representation; drawing; sketching; graphic/spatial modeling; knowledge storage; level of abstraction; geometric descriptions; symbolic references

\begin{tabular}{|c|}
\hline Problem Solving \\
\hline $\begin{array}{l}\text { Ill-defined problem solving; routine/non-routine problems; problem constraints; needs and requirements; } \\
\text { design space/search space; problem-solution interaction; problem situation; task; productive thinking; } \\
\text { adductive thinking; singular problems; repetitive problems; uncertainty; incomplete information }\end{array}$ \\
\hline Design Activities and Design Process \\
\hline $\begin{array}{l}\text { Design actions/moves; design analysis; problem analysis; problem framing/structuring; information gathering; } \\
\text { goal analysis; hypotheses; concept/idea/solution identification/recognition; concept/idea/solution } \\
\text { generation/development; solution analysis; solution clarification; solution evaluation/assessment; solution } \\
\text { selection; knowledge access and retrieval; solution adaptation/adjustment/transformation/development; } \\
\text { decompose/recompose; solution exploration; decision making; cyclical process; linear process; } \\
\text { transitions/phases }\end{array}$ \\
\hline
\end{tabular}

\section{Design Performance and Approach}

Efficiency; opportunism; problem treatment; problem interpretation; problem criticism; learning; reflection; improvement; mental simulation; criticism; superior performance; information prioritization; speed; prediction; elaboration of conjectures about problem

\begin{tabular}{c} 
Conceptualization \\
\hline Abstraction; schema/schemata; idea; concept; pattern; principles/first principles/solution principles; symbolic \\
reference; level of detail
\end{tabular}

Tools and Resources

Existing solution examples; precedents; typologies; visual displays

\section{Analogizing}

Identification; access; retrieval; mapping; correspondences; transference; between-domain sources; within-domain sources; distance; deep relationships; surface relationships; analogical principles

\section{Creativity}

Creative discovery; imagination; exploration; uncertainty; challenge the familiar; novelty; originality; new perspectives; innovation; fluency; elaboration; functionality/usefulness; value; fixation

Expertise can be generally defined as the possession of a large body of domain knowledge and procedural skills $[16,17]$. An expert designer is an individual who has acquired considerable experience through time, master a vast body of well-integrated and consistent domain-specific knowledge [18-20], and has the capability to retrieve, analyze, and apply that knowledge in particular tasks $[16,17,21]$. Expert designers use a systemic approach to deal with the design task [22-24]. They do not follow a linear process, but iterate cyclically, with many transitions through various design stages [18].

While novice designers tend to rely heavily on declarative knowledge and simple or standard heuristics to understand and solve design problems, experts assume the possession of procedural 
knowledge to explore multiple concepts, and adapt them to novel situations [25,26]. Thus, design expertise can be understood as tacit knowledge that entails more procedural know-how than declarative representations (or know-that) [14]. Gaining expertise is therefore seen as transforming declarative knowledge into procedural knowledge [27], which is spontaneously in the form of heuristics, rules of the thumb, integrated procedures and strategies [28] (for an overview see Ball and Ormerod [29]).

Accordingly, design experts possess strategic knowledge, what means that they own knowledge of processes and strategies that they can use during the acquisition or employment of new knowledge [16]. They acquire such strategies by solving related problems time after time. Therefore, they tend to use such strategies quite often and more effectively than novices [30]. They are also very good at making spontaneous decisions regarding what are the best circumstances to use a certain strategy [31]. Their experiential and organized domain-specific knowledge allows them to create a large number of sub-goals by means of problem decomposing approaches that novices lack [13,16,20]. In fact, expert designers are able to carry out opportunistic decompositions for tackling ill-structured design problems [19,32-34].

Novice's strategies are generally related to a depth-first approach to problem solving, meaning successively recognizing, exploring, and analyzing sub-solutions exhaustively and in depth before moving to the next one [13,32]. By using trial and error strategies, they develop only a part of the solution at gradual levels of detail. Experts, in contrast, usually adopt top-down and breadth-first approaches $[35,36]$. Based on years of experience solving an assortment of diverse types of problems in different situations, after exploring multiple concepts, expert designers make preliminary and rapid evaluations of a broad range of design options before opting for one of them [18,33]. Eventually they combine both approaches when the design situation demands it [37].

Differences in the quality of knowledge and problem representations were identified between experts and novices. Design experts possess better representations that capture the more relevant aspects of the design domain [19]. Rather than storing detailed or concrete entities, experts sort information by means of more abstract and meaningful features [38]. Indeed, experts process information at a higher level of abstraction, what enables them to simplify large amounts of information embedded in multiple sources [39]. As a result, they can easily recognize, remember, and interpret relevant knowledge and underlying principles from past solutions accumulated through professional experience, which they utilize extensively and effectively [40]. In many cases, rather than investing a large amount of time in redefining design problems, experts frequently use a solution-driven approach from the initial stages of the process. Employing familiar solutions enables them to act quickly and more efficiently than when relying on problem analysis. This is why some scholars believe that experts can be seen as more solution than problem oriented $[40,41]$. A consequence of this is that experts consider a larger number of alternatives during the design development before making final decisions [18].

Moreover, design experts extensively use knowledge from existing solution examples to create analogies with the problem at hand [42,43]. Whereas novices tend to organize problems that have superficial features in common, experts group problems that are related to solutions by similar principles [44]. Thus, they know how to identify the circumstances under which such solutions best apply to problems. Literature on analogical-reasoning showed that establishing a qualitative analogy is an outcome of the distance between a target (the problem) and source (the solution example). Accordingly, while experts generally establish between-domain analogies, which are remote to the problem at hand, novice designers prefer to use within-domain analogies, which are close to the problem. On the other hand, experts are good at recognizing structural similarities between a source and target. Experience in the design domain contributes to the creation of abstract problem representations, and augments the chances of structural mappings from source to target $[45,46]$. Thus, between-domain analogies are difficult for novices to access and transfer, as they have weak knowledge structures to establish deep analogies [47].

Gaining expertise was of not only observed to be related to the capability of making abstractions and creating analogies, but also to forming design concepts and knowledge schemas [48,49]. Schemas allow 
representing design problems according to key features, and establishing a mapping of relationships with similar problems [46,50]. Expert designers construct their own knowledge schemas, and provide them with personal and singular meanings [51]. These are characterized by intentions, ideals, and values that are used as affordances to direct their design processes [52,53]. As expertise develops, designers access and retrieve familiar design schemas from a collection of examples and precedents-either external or stored in their minds-and adapt them to the design needs $[43,54]$. The use of familiar and well-established precedent solutions allows them to act faster and more effectively than when employing pure problem analysis [40]. Sharedness of schemas and principles is critical to enhance communication and performance in design teams [55], as well as to effectively interact and negotiate with users, clients, and entrepreneurships [56].

Since experts approach design problems more critically, they better understand the needs and constraints of a task [57]. As such, they are skillful enough to perceive more information needs and more information sources, prioritize criteria from such sources, and as noted above, decompose the problem by defining a hierarchy of goals and sub-goals, before making more detailed refinements of the solution $[32,58]$. The opportunistic decomposition of the problem helps them successfully deal with the ill-structure of design problems when searching for solutions $[29,59,60]$.

A reason the master designer can move efficiently in the search space is because he or she stores, accesses, and manipulates information in larger and meaningful cognitive chunks (or blocks of information) than the novice designer $[34,61,62]$. They can identify underlying principles, instead of paying attention to the irrelevant or surface features of the design problems $[13,38]$. Therefore, expert designers are very efficient at framing complex problems from initially incomplete requirements [63]. By recalling chunks of information, they identify from the outset many conflicts that assist them frame the problem, and thereafter search feasible solutions [57,64]. Due to their organized thinking, experts are more efficient than novices in controlling their cognitive activity and performance [13], what enable them to restructure problems without being stuck to the initial conditions [32]. In this regard, Cross [65] found that experts are good at contextualizing the problem in a personal manner, and take a broad systemic approach to the task, in contrast to just applying narrow problem criteria. These not only contribute to dealing with complex and dynamically interrelated design issues that arise when structuring the problem [66], but to speculating and making inferences and conjectures about potential solutions. Elaboration of conjectures has an important function to define and explore problems and solutions in a more integrated fashion [13,57].

Experts also showed evidence of accomplished spatial reasoning skills [56], and to possess knowledge structures that are particularly rich in terms of visual representations [67]. Whereas novice designers were seen to sketch to focus early on concrete forms and design solutions, experts tend to use this tool mainly with the aim of generating ideas and concepts [51,68]. In this regard, more experienced designers are prone to make use of abstract symbolic references to represent their designs, while novices employ formal geometric descriptions more frequently [69]. As the process develops, experts produce representations at various levels of detail, including both conceptual designs and solutions with technical elements [70].

Besides retrieving familiar knowledge from existing design sources, or the systematic generation of expected solutions, design expertise is also about creating something new [27,51]. Important creative outcomes in several domains are frequently made by individuals who possess domain-specific knowledge. Thus, the exploration of original ideas is particularly pertinent to the study of design expertise [71]. From the initial stages of the process, experts unceasingly explore ideas from new perspectives, what leads to unveiling a broader assortment of designs [30]. Casakin [50] observed that while novice designers apply known principles from visual displays that belong to the same domain to the problem at hand, experts use structural principles accessed from remote displays leading to creative solutions. Other researchers found that differences between the creativity of experts and novices can be attributed to their dissimilar cognitive processes [72]. Kokotovich [73] showed that novices, who lack well established skills and methodologies for properly representing their thoughts and ideas, tend 
to run into a solution too early in the design process. This, of course, constraints their creative abilities due to a limited and rather prosaic understanding of the critical aspects of the design problem.

Since design experts can effectively move through the search space, they easily restructure ill-defined problems without being stuck to initial problem conditions [27], which facilitates creative discovery. Thus, expertise in creativity is seen as the ability to organize information in a way that facilitates the intuitive identification of creative and unorthodox solutions, and the employment of heuristic procedures that serve to transform inert knowledge into active exploration [30,74]. Creativity in design expertise is also very powerful in the context of multidisciplinary design teams [38]. Interaction among team members intensifies creativity by meeting different perspectives, information sources, approaches, and technologies. These interplays can trigger unusual thinking, and stimulate experts to think out of the box, and reflect about their own views.

Although expertise has been largely associated to creative potential, some studies showed that in some cases it may also be associated with negative effects [74]. Although experts are more efficient than novices in solving problems, their structured knowledge can also prevent them from looking for creative solutions away from their familiar search space [75]. Thus, instead of taking risks in exploring vague and uncertain and perhaps unsuccessful solutions, their commitment to prior design concepts and known examples can lead to higher levels of fixation than novices [76,77]. Petre [38] summed up expert creative behavior as identification of creative solutions based on developed chunks, which allow moving efficiently through the search space, restructuring problems in support of creative discovery, and using heuristic procedures that transform inert knowledge into dynamic exploration.

\section{Methodology and Research Data}

The research data was collected from leading interdisciplinary design journals (see Table 2), part of which were indexed in the Design Society internet homepage (Accessed: December 2018). The search was limited to the online databases of the seven journals listed in Table 2, even though a wider search was possible. This was done under the assumption that most of the 'design expertise' related articles belonging to these journals would cover the trending themes at any given time.

Table 2. Selected interdisciplinary design journals and corresponding articles organized according to their relevance for the keywords 'expertise' and 'expert'.

\begin{tabular}{cc}
\hline Journal Name & Selected Articles \\
\hline Design Studies & 455 \\
Journal of Engineering Design & 79 \\
Research in Engineering Design & 50 \\
aIEDAM - Artificial Intelligence in Engineering Design Analysis & 78 \\
and Manufacturing & 147 \\
CoDesign & 44 \\
International Journal of Design Creativity and Innovation & 8 \\
International Journal of Design & 861 \\
Total & \\
\hline
\end{tabular}

The collection and selection of the data involved multiple steps. Initially, articles were identified using keywords such as expertise, expert, and semantic variants of the term such as proficient and skillful. A preliminary reading of the abstracts of the resulting articles was conducted to make a qualitative filtering according to their relevance for the study. For instance, articles related to expert systems or empirical studies where expert feedback was obtained to validate findings, were considered to have no direct relevance to the present study, and therefore were filtered out. Finally, the filtering and grouping process led to the inclusion of 861 article abstracts into the corpus for text analysis. Table 2 shows the selected design journals and the number of articles included in the study after the filtering process.

Why LSA on abstracts and not the full-text? From LSA perspective, abstracts have less noise in the data since they mostly provide uninterrupted and self-containing text that summarizes the whole 
paper. In contrast, in the main text of the paper, authors often use figures and tables that are integral to communicating the key themes of the paper. Since figures and tables are not accessible to semantic text analysis, it is likely that LSA on the main body of the paper will miss some critical information. Another disadvantage of carrying out an LSA analysis through the main text is that authors may repeat the same themes to emphasize key messages, and this could affect the term frequency calculations [9]. Consequently, in LSA based studies, use of abstracts for identifying thematic patterns in the literature is an accepted approach, e.g., [10-12].

\subsection{Data Analysis}

The collected dataset (corpus) was subjected to LSA $[8,78,79]$ to identify the latent concepts within the textual data at the semantic level [80]. LSA uses a set of algorithms to convert unstructured text into structured data objects, and analyze these data objects to identify patterns for the discovery of knowledge [81]. The main idea behind LSA was to collect all the contexts belonging to the words in the corpus, and derive associated factors that represent related concepts.

In this paper, a factor is a latent class representing multiple observed entities which have similar patterns that are associated with the latent class. LSA was used to cluster thematic patterns at the different levels of detail using 12-, 20-, 50-, and 80-factor analyses. For example, in a 12-factor analysis, all the entities that were found in the corpus to be relevant to the analysis were classified and represented through 12 latent classes. Initially, five and eight factors were also considered for analysis. However, given the large variety of terms associated with design expertise in literature, anything less than 10 factors was deemed too abstract to be labeled in a way that would provide useful insights. Accordingly, an analysis on five and eight factors was not continued further.

Thus, each factor represented a certain part of the overall observed entities, whereas the factors were organized in the order of the entities that they explain. A sample representation of factors and their associated entities is presented in Table 3. In any analyzed text, multiple words may share the same meaning, and one word may have many synonyms in different contexts. LSA "loads" the words that share the same meaning to their associated concept, and also "loads" one word to various latent semantics other than its main associated concept.

Table 3. Latent classes and corresponding entities identified in the 12-factor analysis.

\begin{tabular}{|c|c|c|}
\hline & Latent Classes & Entities \\
\hline F12.1 & $\begin{array}{l}\text { Training for } \\
\text { improving quality of } \\
\text { outcome }\end{array}$ & $\begin{array}{l}\text { Maxim, situated, coach, quantify, idea_product, knowledg_structur, us } \\
\text { framework, prospect, durat, fact, interact_experi, meaning, } \\
\text { articul_design, unstructur. media_design, lean, ill, meet_requir, } \\
\text { novic_design, partner. novic }\end{array}$ \\
\hline F12.2 & $\begin{array}{l}\text { Scoping and framing } \\
\text { of ill-defined } \\
\text { problems }\end{array}$ & $\begin{array}{l}\text { III, us_techniqu. articul_design. applic_condit, coach. hinder, } \\
\text { fixat_effect, situated, durat, cross, interact expert, industri_engin, } \\
\text { assumpt. problem_design, schon, major, develop creativ. service, } \\
\text { examin_design, session, idea_product, static }\end{array}$ \\
\hline F12.3 & $\begin{array}{l}\text { Interaction and } \\
\text { experience-based }\end{array}$ & $\begin{array}{l}\text { interact_experi, cross, quantify, ill, articul_design, develop_creativ, } \\
\text { model_gener, durat, coach, applic_condit, hinder, situated, us_techniqu, } \\
\text { result_detail, assumpt, us_framework, service, entir, findindic, lean, van, } \\
\text { master }\end{array}$ \\
\hline F12.4 & $\begin{array}{l}\text { Model-driven for } \\
\text { idea-solutions }\end{array}$ & $\begin{array}{c}\text { model_gener, idea_product, situated, articul_design, quantify, static, } \\
\text { deliber, assumpt. interact_experi, ill, build_user, durat, sketch_design, } \\
\text { coach, facility, nnodel_tool, partner, advantage, fixat_effect, model_valid, } \\
\text { primari_school, group_perform }\end{array}$ \\
\hline F12.5 & Operations and tools & $\begin{array}{c}\text { oper_process, musician, design_heurist, ill, coach, master, applic_condit, } \\
\text { interact_experi, analys_us, us framework, fund, develop_user, divers, } \\
\text { freshmen, hi, quantify, design_invoiv, paco, futur_develop, van, } \\
\text { articul_design. emerg_design }\end{array}$ \\
\hline
\end{tabular}


Table 3. Cont.

\begin{tabular}{|c|c|c|}
\hline & Latent Classes & Entities \\
\hline F12.6 & $\begin{array}{l}\text { Mastery and } \\
\text { assessment }\end{array}$ & $\begin{array}{c}\text { Master, interact_experi. articul_design, sketch_design, maxim, } \\
\text { fixat_effect, hi, review_literatur, quantify, complementari, us comput. } \\
\text { situated, lean, method_assess, model_gener, failure, durat. ill, partner. } \\
\text { prospect, fact. Descript }\end{array}$ \\
\hline F12.7 & $\begin{array}{l}\text { Individual and } \\
\text { teamwork experience }\end{array}$ & $\begin{array}{l}\text { individu_team, emphasi_place, driven_process, situated, convent, } \\
\text { inhabit, applic_condit, interact_experi, articul_design. ill, hi, exclude, } \\
\text { knowledg_structur, complementari, equip, group_perform, } \\
\text { review_literatur. innov_activ, idea_product, service, musician, } \\
\text { advantage }\end{array}$ \\
\hline F12.8 & $\begin{array}{l}\text { Training for blending } \\
\text { and concept } \\
\text { development }\end{array}$ & $\begin{array}{l}\text { Static, articul_design. conceptu_blend, coach, fact, interact_experi, us } \\
\text { techniqu, equip, paco, quantify, us_comput, examin_design, maxim, } \\
\text { samara, constant, us framework, idea_product, design_base, assumpt, } \\
\text { design_conceptu, model_gener, fr }\end{array}$ \\
\hline F12.9 & $\begin{array}{l}\text { Quality and } \\
\text { assessment }\end{array}$ & $\begin{array}{l}\text { review_literatur, maxim, quantify. lean, durat, articul_design. coach, } \\
\text { descript, interact_experi. complementari, attitud_design, designinnov, } \\
\text { analys_us, secondli, knowledg_structur, design_qualiti, prospect, cross, } \\
\text { design_particip, ill, us_techniqu, model_gener }\end{array}$ \\
\hline F12.10 & $\begin{array}{l}\text { Creativity and added } \\
\text { value }\end{array}$ & $\begin{array}{c}\text { provid_insight, develop_creativ, complementari, assumpt, applic_condit, } \\
\text { situated, equip, ill. conceptu_blend, interact_experi, advantage. } \\
\text { idea_product, driven_process, emerg_design. develop tool, } \\
\text { design_emploi, design_altem, fact, prospect, fr, underli_design, } \\
\text { problem_us }\end{array}$ \\
\hline F12.11 & $\begin{array}{l}\text { Reflective, } \\
\text { participatory, and } \\
\text { interactive } \\
\text { approaches }\end{array}$ & $\begin{array}{l}\text { us_techniqu, articul_design. idea_product, quantify, problem_us, } \\
\text { assumpt, coach, examin_design, paco, situated, participatori_action, ill, } \\
\text { interact_experi, primari_school. schan, nnitig, lean, deliber, } \\
\text { us_framework, prospect, us_comput, applic_condt }\end{array}$ \\
\hline F12.12 & $\begin{array}{l}\text { Design know-how } \\
\text { and concept } \\
\text { exploration }\end{array}$ & $\begin{array}{l}\text { Hinder, paco, conceptu_blend, situated, analys_us, ill, us_framework. } \\
\text { durat, quantify, investig_role, optimis. applic_condit, articul desn, static, } \\
\text { fact, extend, interact_experi, equip, examin_design, prospect, maxim, } \\
\text { develop_user }\end{array}$ \\
\hline
\end{tabular}

LSA differs from traditional factor analysis in using Singular Value Decomposition (SVD) to reduce the dimension of the original data. This helped to present the collected 861 papers under the categories. By employing SVD, LSA generated two sets of loadings in a matrix format: one aimed for the terms and another for the documents. Each factor in the matrices is associated with a high-loading term and a high-loading document, where each factor represented a research theme in the corpus.

Higher term/document loading values for each factor indicates a greater possibility that the related term/document discloses a key theme. The level of detail considered for identifying research themes is modified by changing the number of factors in the analysis. Lower level factor aggregation represents common research areas, whereas higher level factor aggregation is an indicator of main research themes. Since the use of LSA for identifying thematic patterns in literature is well-established and the techniques are well documented, e.g., [9-12], this paper only briefly outlines the key steps involved in the process of analysis.

3.1.1. Step 1: Applying Text-Mining Process Including Tokenization, Stemming, Stop Word Filtering, N-Grams in Text-Mining Software

The following series of text-mining procedures was applied within Rapidminer 5.0 as follows: (i) abstracts were tokenized with non-letter separators such that each abstract was aggregated to singular words that make it an individual word-bag; (ii) all the letters in the word bags were transformed to lowercase; (iii) stop words of English language such as "and," "the," and "so" were predefined in Rapidminer 5.0 (in addition, keywords like "expert" and "expertise" that are used during document 
collection were custom defined and removed from the word-bags.); (iv) tokens of the words that had less than two letters were removed, since they do not add any meaning to the words; (v) term stemming techniques were applied to the word-bags in order to remove word variations; i.e., the words "experts" and "expertise" were transformed to a single token "exper-"; and, (vi) the n-gram model was applied, which creates word groups that were considered as an individual token in the word-bag. For example, the phrase "Design Expertise" or "Design Expert" was aggregated to tokens "Design-Exper" as a bigram. Similarly, the phrase "Expert design methodology" or "Expert design method" was aggregated to token "Exper-Design-Method" as a trigram.

\subsubsection{Step 2: Output of Text Mining Processes: Term Occurrences (TO) and Term Reduction}

Initially, the dataset was analyzed using both bigrams and trigrams. Term occurrences were sorted in descending order. In order to reduce the dimension, the entities that occurred once, and the entities that appeared in only one abstract, were removed from the matrix. However, during the dimensionality reduction, approximately $90 \%$ of the entities were removed from the matrix due to their existence in one document or only one time. This included most of the three-word entities, provided that these documents did contribute in any meaningful way to the entire corpus. Therefore, the trigram analysis was discarded, and instead the bigram analysis was used for further analysis. Additionally, following the steps in [82], the entities that appeared less than five times in the corpus were removed from the matrix.

\subsubsection{Step 3: Calculating Term Frequency-Inverse Document Frequency (TF-IDF), SVD, and} Factor Loadings

The raw $\mathrm{t}-\mathrm{d}$ matrix was transformed through weighting and normalization methods. Term frequency (tf) and inverse document frequency (idf) values of each entity were calculated consecutively $[79,83,84]$. The tf-idf value of each entity represents how important that entity is to a corpus. The tf-idf values increase as the occurrence of the entity increase. However, in counterbalance to this, the frequency of words in the corpus help to account for the fact that some entities are more common than others [85]. The tf-idf, which was transformed from the raw $t-d$ matrix, was subjected to SVD and decomposed to term-to-concept matrix, document-to-concept matrix, and square roots of eigenvalues (singular values), whereas strengths of concepts appear in descending order. Multiplication of term-to-concept and singular value matrixes produces the factor loadings of terms for each study. The multiplication of document-to-concept matrix and singular value matrix generates the factor loadings of documents for each research pattern. The maximum number of factors generated in this way is equal to the number of documents (i.e., 861). To assess the principal research areas and the research themes, the number of factors was adjusted by reducing the dimension of factor loading matrix.

\subsubsection{Step 4: Rotation of Factor Loadings and Factor Threshold Values for Research Areas and Themes}

In factor analysis, the rotation of the matrix displays the loadings of variables on factors, and simplifies the factor associations. Entities with a high loading value in factor are associated with a theme. Through rotation of factor axes, the loading of an entity on one factor is maximized while minimizing its loading on other factors. Associated high-loading terms and documents of each research pattern are clustered and matched. Varimax rotation [86] was applied to the term and document loadings. Aggregation level varies for each factor solution. In order to parse the significant and non-significant entities/documents, an appropriate threshold value was selected for each factor solution following the approach used in [9]. Documents with factor loading below the related threshold value were eliminated. 


\subsubsection{Step 5: Factor Evaluation and Research Theme Labeling}

In each factor solution, high-loading entities and documents within the calculated threshold value were grouped with the absolute values of the loadings in descending order. High-loading entities and documents were reviewed and labeled by the authors (12 through 20, 50, and 80 factors).

The process of labeling is a subjective and iterative exercise, dependent on interpretation and on the labels selected by the researcher(s) naming a thematic cluster. Therefore, in the first round the clustered themes were labeled independently by the two authors. After the initial labeling, the labels of the two authors were compared. At this stage, nearly $25 \%$ of the labels differed between the two authors. Following a discussion, authors agreed on most of the labels, leaving only $5 \%$ for which agreement was not reached. After a third round of discussion that included three doctoral students, a final agreement was obtained for the remaining themes.

\section{Results and Discussion}

Table 4 lists the results of the 12-, 20-, 50-, and 80- factor analyses. The analysis at different factor levels helped to gain better insight into 'expertise in design' related themes at different levels of detail. As discussed previously, the labeling of the factors is a subjective process, based on an interpretation of the clustering of the terms contained within the factors. Accordingly, similarities were identified in some themes at different levels of detail.

Table 4. Themes identified in the 12-, 20-, 50-, and 80-factor analyses.

\begin{tabular}{|c|c|}
\hline \multicolumn{2}{|c|}{12 Factors } \\
\hline Training for improving quality of outcome (F12.1) & Individual and team experience (F12.7) \\
\hline Scoping and framing of ill-defined problems (F12.2) & Training and concept development (F12.8) \\
\hline Interaction and experience-based (F12.3) & Quality and assessment (F12.9) \\
\hline Model-driven for idea-solutions (F12.4) & Creativity and added value (F12.10) \\
\hline Operations and tools (F12.5) & $\begin{array}{l}\text { Reflective, participatory, and interactive approaches } \\
\text { (F12.11) }\end{array}$ \\
\hline Mastery and assessment (F12.6) & Design know-how and concept exploration (F12.12) \\
\hline \multicolumn{2}{|c|}{20 Factors } \\
\hline Context and fixation in ill-defined problems (F20.1) & $\begin{array}{l}\text { Forecasting by making conjectures about ideas } \\
\qquad(\mathrm{F} 20.11)\end{array}$ \\
\hline Mastery and breadth of skills (F20.2) & Managing uncertainty and complexity (F20.12) \\
\hline Collaboration experience (F20.3) & Training and experience (F20.13) \\
\hline Interaction and solution focus (F20.4) & Design management (F20.14) \\
\hline Operations and design process (F20.5) & Exploration and analysis (F20.15) \\
\hline Efficiency in novel concepts and solutions (F20.6) & Idea and creativity development (F20.16) \\
\hline Individual and team performance (F20.7) & Design techniques and methods (F20.17) \\
\hline Co-creation of concepts (F20.8) & Concepts and knowledge-based design (F20.18) \\
\hline Assessment: effectiveness and efficiency (F20.9) & Framing and assessing design (F20.19) \\
\hline Idea generation process (F20.10) & Assumptions and design management (F20.20) \\
\hline \multicolumn{2}{|c|}{50 Factors } \\
\hline Ill-defined problem and reflective practice (F50.1) & $\begin{array}{c}\text { Process and outcome: alternative solutions for } \\
\text { ill-defined problems (F50.26) }\end{array}$ \\
\hline Efficiency and mastery (F50.2) & Efficiency and learning (F50.27) \\
\hline Interaction and representation (F50.3) & Decision criteria and value (F50.28); \\
\hline Effective design (F50.4) & Search and reflection (F50.29) \\
\hline
\end{tabular}


Table 4. Cont.

\begin{tabular}{|c|c|}
\hline \multicolumn{2}{|c|}{50 Factors } \\
\hline Heuristics and techniques (F50.5) & Dealing with facts and fiction (F50.30) \\
\hline Modeling tools (F50.6) & Knowledge structure and innovation (F50.31) \\
\hline Team and problem context (F50.7) & Modelling process (F50.32) \\
\hline Combine concepts and iterate (F50.8) & Deliberation and knowledge exchange (F50.33) \\
\hline Efficiency and assessment (F50.9) & Control (F50.34) \\
\hline Reflection and design strategies (F50.10) & Performance assessment strategy (F50.35) \\
\hline Articulation and knowledge elicitation (F50.11) & Iterative decision making (F50.36) \\
\hline Dealing with complexity (F50.12) & Team knowledge and performance (F50.37) \\
\hline Sharing experiences and mentoring (F50.13) & Emergence and discovery (F50.38) \\
\hline $\begin{array}{l}\text { Pro-active and multi-disciplinary/interdisciplinarity } \\
\text { (F50.14) }\end{array}$ & Contextual knowledge (F50.39) \\
\hline Conjectures, investigations, and analysis (F50.15) & Analysis and review (F50.40) \\
\hline Insights and assessment (F50.16) & Alternative solutions (F50.41) \\
\hline Creative skills development (F50.17) & Participatory action and concept finding (F50.42) \\
\hline Concept and context awareness (F50.18) & Multiple perspectives (F50.43) \\
\hline Evaluating effectiveness of design process (F50.19) & Measuring user-product experience (F50.44) \\
\hline Design assumptions and design strategy (F50.20) & Dealing with complexity (F50.45) \\
\hline Reflection and representation (F50.21) & Systematic analysis and knowledge transfer (F50.46) \\
\hline Participation and engagement (F50.22) & Representation, mastery and control (F50.47) \\
\hline Methodical approach and structuring (F50.23) & $\begin{array}{l}\text { Design experience and computational techniques } \\
\text { (F50.48) }\end{array}$ \\
\hline $\begin{array}{l}\text { Interaction, participation and learning experience } \\
\text { (F50.24) }\end{array}$ & $\begin{array}{l}\text { Reasoning and expanding knowledge for novelty } \\
\text { (F50.49) }\end{array}$ \\
\hline Complementary perspectives (F50.25) & Suggestions for design development (F50.50) \\
\hline \multicolumn{2}{|c|}{80 Factors } \\
\hline Engagement (F80.1) & Develop design alternatives (F80.41) \\
\hline Level of expertise (F80.2) & Conceptualization and ideation (F80.42) \\
\hline Integration (F80.3) & $\begin{array}{l}\text { Considering alternatives and being non-fixated } \\
\text { (F80.43) }\end{array}$ \\
\hline Knowledge structure (F80.4) & User-centered problem-solution co-evolution (F80.44) \\
\hline Operation techniques and tools (F80.5) & Dealing with the unknown (F80.45) \\
\hline Context and conditions (F80.6) & Systemic and concept driven (F80.46) \\
\hline Team interaction (F80.7) & Communication and representation (F80.47) \\
\hline Reflection and concept formation (F80.8) & Design procedures and rules (F80.48) \\
\hline Efficient and effective (F80.9) & Broaden knowledge (F80.49) \\
\hline Control process (F80.10) & User participation and experiential learning (F80.50) \\
\hline Product modelling (F80.11) & Training and experience (F80.51) \\
\hline User participation (F80.12) & Exchanging complementary knowledge (F80.52) \\
\hline Training and learning (F80.13) & User awareness and interaction (F80.53) \\
\hline Knowledge base (F80.14) & Teamwork (F80.54) \\
\hline Review, analysis, and investigation (F80.15) & Methodology and process (F80.55) \\
\hline Skills development (F80.16) & Situated and reflective practice (F80.56) \\
\hline
\end{tabular}


Table 4. Cont.

\begin{tabular}{|c|c|}
\hline \multicolumn{2}{|c|}{80 Factors } \\
\hline Assessment and judgement (F80.17) & Knowledge elicitation (F80.57) \\
\hline Clarity on facts and fiction (F80.18) & Design reuse and strategies (F80.58) \\
\hline Measurement (F80.19) & Knowledge typology and representation (F80.59) \\
\hline Design conjectures (F80.20) & Dealing with complex products (F80.60) \\
\hline Contextual knowledge (F80.21) & Suggestions for continuous improvement (F80.61) \\
\hline $\begin{array}{l}\text { Domain experience, participation, and involvement } \\
\text { (F80.22) }\end{array}$ & Involvement and participation (F80.62) \\
\hline Mental block (F80.23) & Design interaction (F80.63) \\
\hline Novice and expert interaction (F80.24) & Design generation as synergistic activity (F80.64) \\
\hline Efficiency and creativity (F80.25) & $\begin{array}{l}\text { Capturing design intentions and requirements } \\
\text { (F80.65) }\end{array}$ \\
\hline Exhibition of expertise (F80.26) & Team collaboration and interaction (F80.66) \\
\hline Predict and anticipate (F80.27); & Design attitudes and iteration (F80.67) \\
\hline Inform decision making (F80.28) & Team performance (F80.68) \\
\hline Discussing and share (F80.29) & Problem decomposition and process (F80.69) \\
\hline Develop context awareness (F80.30) & Finding solutions for ill-defined problems (F80.70) \\
\hline $\begin{array}{l}\text { Structuring and formulating measures for innovation } \\
\qquad(\mathrm{F} 80.31)\end{array}$ & Training for innovation (F80.71) \\
\hline Modelling and assessment (F80.32) & Team management (F80.72) \\
\hline Deliberate practice (F80.33) & Information and fact based (F80.73) \\
\hline Control strategy (F80.34) & Value addition for creativity (F80.74) \\
\hline Discerning and dealing with complexity (F80.35) & Experience and reflective decision process (F80.75) \\
\hline Design evaluation (F80.36) & Creating new knowledge (F80.76) \\
\hline Proactive process (F80.37) & Skills and knowledge for de-fixation (F80.77) \\
\hline Emergent design and development process (F80.38) & Making sense of problem context (F80.78) \\
\hline Goal oriented (F80.39) & Complementary perspectives (F80.79) \\
\hline Exploration and conjecturing (F80.40) & Detailing and uncovering (F80.80) \\
\hline
\end{tabular}

\subsection{Review of 12-Factor Analysis}

This section briefly reviews each of the research areas that emerged through the 12-factor analysis. Moreover, several similarities were observed when comparing the themes identified in the 12-factor analysis and the manual literature review carried out at the beginning of the manuscript (See Table 5). In some cases, the factors were found to superpose with more than one category.

Table 5. Themes identified using the Latent Semantic Analysis (LSA) technique for the 12-factor analysis and the manual literature review.

\begin{tabular}{llc}
\hline \multicolumn{1}{c}{ 12-Factor Analysis } & Manual Literature Review \\
\hline F12.1 & Training for improving quality of outcome & \\
\hline F12.2 & Scoping and framing of ill-defined problems & $\begin{array}{c}\text { Problem solving } \\
\text { Design activities and design process }\end{array}$ \\
\hline F12.3 & Interaction and experience-based & \\
\hline
\end{tabular}


Table 5. Cont.

\begin{tabular}{llc}
\hline \multicolumn{1}{c}{ 12-Factor Analysis } & Manual Literature Review \\
\hline F12.4 & Model-driven for idea-solutions & Knowledge strategies \\
\hline F12.5 & Operations and tools & $\begin{array}{c}\text { Knowledge strategies } \\
\text { Tools and resources }\end{array}$ \\
\hline F12.6 & Mastery and assessment & $\begin{array}{c}\text { Design performance and design approach } \\
\text { Design activities }\end{array}$ \\
\hline F12.7 & Individual and teamwork experience & Analogizing \\
\hline F12.8 & Training for blending and concept development & Design activities and design process \\
\hline F12.9 & Quality and assessment & Creativity \\
\hline F12.10 Creativity and added value & Design performance and design approach \\
\hline F12.11 & Reflective, participatory, and & Domain knowledge \\
\hline F12.12 & Design know-how and concept exploration & Design activities and design process \\
\hline
\end{tabular}

\subsubsection{Training for Improving Quality of the Outcome}

This area combines two key aspects of expertise, 'training' and 'quality'. Training not only refers to being taught or coached under supervision, but is also concerned with self-learning and practice. Whereas training sets a focus on the effort involved in the development of expertise [1], the second aspect denotes that training experts can set higher levels of benchmark in the expected quality of the outcome. Thus, training provides the means needed to improve and achieve higher quality outcomes.

\subsubsection{Scoping and Framing of Ill-Defined Problems}

This area is concerned with two frequently related aspects of expertise: 'framing' and dealing with 'ill-defined problems'. Framing and scoping refer to the ability of experts to clearly formulate and identify what the crux of the problem is, and to focus on the most relevant issues demanding a solution, e.g., $[63,64]$. However, the ill-defined nature of design problems is a major concern reflecting that a potential solution space is determined by the way that a design problem is formulated. The ability of experts to define and frame ill-defined design problems contributes to arriving at better solutions. This factor is closely related to two categories identified in the traditional literature review: one is Design activities, which includes problem framing/structuring and the other is Problem solving, focusing on ill-defined problems.

\subsubsection{Interaction and Experience-Based}

In addition to knowledge and skills, experience is a basic condition of expertise [5] necessary for reaching successful solutions [87]. The present factor adds to these the view that the ability to build on interactions with others when solving problems, and the exposure to other disciplines, supported by the sharing and exchange of experiences are also critical aspects to enhance expertise.

\subsubsection{Model-Driven for Idea-Solutions}

According to literature, experts are known for their large, organized, and well-integrated structures of knowledge. These enable them to encode and represent significant domain-specific knowledge. Models, on the other hand, offer the means to articulate and represent the external world in abstract, 
conceptual, and often symbolic terms. Models allow to make assumptions, interpretations, and decisions at various levels of abstraction under different situations [2]. What the present factor adds to these, is that due to their well-developed knowledge structures of problem contexts, experts are driven by models that enable them to generate ideas and develop solutions. The present factor shares similarities with the category identified from the traditional literature review dealing with Knowledge strategies. In particular, the strategic knowledge used by experts when tackling a design problem, mainly the solution-driven approach [41].

\subsubsection{Operationalizing and Tools}

Using the right methods and tools is critical to deal with design problems. Experts are known to possess a wide repository of well-established tools, procedures, and methods [29,68]. This increases their chances of choosing adequate approaches to tackle design problems, when operationalizing ill-defined contexts. The present pattern reaffirms that tools, procedures and methods embrace techniques such as search strategies, best practices and processes-including those related to managing tasks and context, as well as external aids relevant to the problem. Similarities were found between the Operationalizing and tools factor and the categories of Knowledge strategies and Tools and resources from the traditional literature review. While the former focuses on the different strategies employed by designers for solving design problems, the latter is about the means that designers use in support of the design problem solving activity [71].

\subsubsection{Mastery and Assessment}

Design literature defines mastery as an outstanding level of competence, knowledge, and skills that expert designers possess $[13,21]$. The present pattern suggests that assessment demands expertise. Thus, master designers have high levels of breadth and depth that they employ in not only understanding a problem, but also assessing the design situation. By efficiently assessing design outcomes in the framework of major design goals, needs, and requirements, master designers are able to focus on the important aspects of the design situation. The factor was found to be related to Design performance and design approach, and to Design activities categories from the traditional literature review. Above all, Mastery has to do with superior performance [4], characterizing all the themes in the former category.

\subsubsection{Individual and Teamwork Experience}

Teamwork was confirmed to be a fundamental factor for acquiring design experience. Design experience entails the capability of complementing and integrating divergent ideas and perspectives, including multidisciplinary knowledge and skills. The design literature discusses experience both in terms of the individual and his or her ability to work as a team [42]. When interacting with other team members, sharing individual knowledge affects not only the design outcomes produced, but also the coordination and communication of tasks, processes, and activities [55].

\subsubsection{Training for Concept Blending and Concept Development}

The ability to develop and blend concepts, and build on new ideas and concepts, is known in design literature as a most critical stage of the design process [23]. Generally speaking, blending is defined as the process of mixing. In the design domain blending is concerned with the ability to connect between two domains that are remote to the design problem, which can contribute largely to idea generation and concept development. Since concept development is by no means an inborn feature of the designer, the current factor stresses that coaching designers to enhance their knowledge and skills can contribute largely to this aim. Often, training in concept blending and concept development requires experience over multiple problems and disciplinary domains, and abstraction skills. With experience, experts acquire the ability to reflect and self-train themselves in concept development. In this factor, concept blending was found to be in some way related to Analogizing, identified in the traditional literature review $[43,44]$. It is well-known that creating a qualitative analogy is a consequence 
of the distance between the design problem and the source example. Experts excel in establishing between-domain analogies, which are distant to the design problem. As such, these kinds of analogies support the development of outstanding concepts.

\subsubsection{Creativity and Added Value}

In domains such as design, the production of creative and worthwhile outcomes is particularly relevant. Existing literature accounts that the creativity of the designers and their ability to generate innovative outcomes were studied extensively, specifically in relation to expertise [71]. As noted before, rather than applying familiar knowledge from existing sources to deal with a problem, or the mechanical use of expected solutions, design expertise is also about creating something novel [51]. In addition to the ability to generate unfamiliar outcomes, the present pattern suggests that as expertise develops, creativity in design should be concerned with the production of solutions with added value (e.g., social, cultural, environmental values) [88]. This factor was found to be strongly related to the Creativity category observed in the traditional literature review. This suggests that the topic is at the core of design expertise.

\subsubsection{Quality and Assessment}

In spite of the significance of design creativity and innovation, many new products failed due to their lack of satisfactory quality. The expert ability to understand and assess attributes that can affect the quality of a design is another important theme identified in literature [89]. This includes the knowledge and procedural skills necessary to employ tools and methods [90] to enhance quality control, delivery, and assessment.

\subsubsection{Reflective, Participatory, and Interactive Approaches}

Expertise in design is a thoughtful activity that was seen to be associated with reflective practice, wherein designers self-assess their design process and own way of working [91,92]. Interestingly, literature mainly focuses on the reflection of the individual expert. However, reflection about what has been done and what needs to be achieved can not only be performed by an individual designer, but can also be the outcome of a participatory practice in a design team, as the present factor suggests. During participatory activities, reflective practice can be enhanced while maintaining interactions with other experts. This can contribute to a sharing of knowledge and gaining a deeper understanding of the design situation [93], and thus to the development of expertise. Consequently, this factor was found to be party related to the Design performance and approach category found in traditional literature, mainly reflection, but at the individual level.

\subsubsection{Design Know-How and Concept Exploration}

This theme emphasizes know-how as a critical element necessary for the development of expertise. As discussed before, experts are able to transform declarative representational knowledge (know about or know that) into procedural knowledge (know-how) [14]. Indeed, design expertise encompasses more procedural knowledge (know-how) than declarative representations (know-that) [26]. In addition to these, what the present factor indicates is that procedural knowledge is essential to not only structure the design problem, but also to guide the exploration of design concepts and ideas, while searching for alternative solutions. Accordingly, this factor showed to be strongly related to two categories from the traditional literature concerned with Domain knowledge and Design activities and design process.

The review of the themes identified in the 12-factor analysis shows congruence with the main topics from the literature review of leading interdisciplinary design journals. This is interesting considering that the analyses were carried out using two independent approaches. However, what the present study adds to the existing literature about design expertise, is that the mapping of the factors shows how themes are related across the different factors, and at various levels of detail (see Tables 6 and 7. For example, it can be observed that whereas some themes emerged at the 50- and 
80 -factor analyses respectively, they were absent in the 12- and 20-factor analyses. Thus, the factor analyses helped to understand the relative emergence of a theme in relation to the others. This should be considered an important contribution to the design expertise field, and to design education in particular, as is discussed in the following section.

Table 6. Mapping themes from 12-factor analysis to themes in 20-, 50-, and 80-factor analyses.

\begin{tabular}{|c|c|c|}
\hline F12 & Themes & 12+ - Mapping with 50-Factor and 80-Factor Terms \\
\hline F12.1 & $\begin{array}{l}\text { Training for improving } \\
\text { quality of outcome }\end{array}$ & $\begin{array}{l}\text { [Training: } 20.13,50.27,80.13,80.16,80.50,80.51] \\
\quad \text { [Quality of outcome: } 20.6,50.4,80.9,80.36]\end{array}$ \\
\hline F12.2 & $\begin{array}{l}\text { Scoping and framing of } \\
\text { ill-defined problems }\end{array}$ & $\begin{array}{l}\text { [Scoping/framing: } 20.19,50.43,80.31,80.35,80.79] \\
\text { [Ill-defined:20.1, 20.12, 50.1, 50.12, 50.45, 80.35, 80.60] }\end{array}$ \\
\hline F12.3 & $\begin{array}{l}\text { Interaction and } \\
\text { experience-based }\end{array}$ & $\begin{array}{c}\text { [Interaction: } 20.4,20.8,50.3,50.13,50.22,50.33,80.1,80.7,80.24, \\
\text { 80.29, 80.53, 80.54, 80.62, 80.63, 80.66] } \\
\text { [Experience: } 20.3,20.13,50.13,50.24,50.44,50.48,80.22 \\
80.49,80.51,80.52,80.75]\end{array}$ \\
\hline F12.4 & $\begin{array}{l}\text { Model-driven for } \\
\text { idea-solutions }\end{array}$ & [Model-driven: 20.17, 50.6, 50.32, 80.11., 8032, 80.55] \\
\hline F12.5 & Operations and tools & $\begin{array}{c}\text { [Operations: } 20.5,80.5] \\
\text { [Tools: } 20.17,50.6,50.48,80.5]\end{array}$ \\
\hline F12.6 & $\begin{array}{l}\text { Mastery and } \\
\text { assessment }\end{array}$ & $\begin{array}{c}\text { [Mastery: 20.2; 50.2; 50.47; 80.2; 80.22; 80.24; 80.26] } \\
\text { [Assessment/evaluation /judgement: 20.9; 20.19; 50.9; 50.16; 50.19; } \\
\text { 50.36; 80.17; 80.32; 80.36] }\end{array}$ \\
\hline F12.7 & $\begin{array}{l}\text { Individual and team } \\
\text { experience }\end{array}$ & $\begin{array}{l}\text { [Team: } 20.7 ; 50.7 ; 50.37 ; 80.7 ; 80.54 ; 80.66 ; 80.68 ; 80.72] \\
\quad \text { [Experience: } 20.3 ; 20.13 ; 80.22 ; 80.50 ; 80.51 ; 80.75]\end{array}$ \\
\hline F12.8 & $\begin{array}{l}\text { Training and concept } \\
\text { development }\end{array}$ & $\begin{array}{l}\text { [Training: 20.13; 50.13; 50.27; 80.13; 80.50; 80.51; 80.71] } \\
\text { [Concept/idea: 20.6; 20.8; 20.10; 20.11; 20.16; 20.18; 50.8; 50.18; } \\
\text { 80.42; 80.46] } \\
\text { [Development: } 20.16 ; 50.17 ; 50.50 ; 80.16 ; 80.30 ; 80.38 ; 80.41]\end{array}$ \\
\hline F12.9 & Quality and assessment & $\begin{array}{l}\text { [Assessment/evaluation/judgement: } 20.9 ; 20.19 ; 50.9 ; 50.16 ; 50.19 ; \\
50.36 ; 80.17 ; 80.32 ; 80.36 \text { ] }\end{array}$ \\
\hline F12.10 & $\begin{array}{l}\text { Creativity and added } \\
\text { value }\end{array}$ & $\begin{array}{c}\text { [Creativity/innovation/novelty: } 20.16 ; 50.17 ; 50.31 ; 50.49 ; 80.25 ; \\
\text { 80.74; 80.31;80.71] } \\
\text { [Value addition: } 50.28 ; 80.74]\end{array}$ \\
\hline F12.11 & $\begin{array}{c}\text { Reflective, } \\
\text { participatory, and } \\
\text { interactive approaches }\end{array}$ & $\begin{array}{l}\text { [Interaction/iterate: } 20.4 ; 50.8 ; 50.3 ; 50.36 ; 50.33 ; 80.7 ; 80.24 ; 80.53 ; \\
\quad 80.63 ; 80.66 ; 80.67] \\
\text { [Reflective practice/conjectures/assumptions: } 20.11 ; 20.20 ; 50.1 ; \\
\text { 50.10; 50.15; 50.21; 50.29; 80.8; 80.20;80.56; 80.75] } \\
\text { [Participation/involvement/engagement/collaboration: } 20.3 ; 50.22 ; \\
\quad 80.1 ; 80.12 ; 80.50 ; 80.62 ; 80.66]\end{array}$ \\
\hline F12.12 & $\begin{array}{l}\text { Design know-how and } \\
\text { concept exploration }\end{array}$ & $\begin{array}{r}\text { [Knowledge/skills: } 20.2 ; 20.18 ; 50.11 ; 50.17 ; 50.31 ; 50.33 ; 50.37 ; \\
50.39 ; 50.46 ; 80.4 ; 80.14 ; 80.16 ; 80.21 ; 80.45 ; 80.49 ; 80.52 ; 80.57 ; 80.59 ; \\
80.76 ; 80.77] \\
\text { [Concept/idea: } 20.6 ; 20.8 ; 20.10 ; 20.11 ; 20.16 ; 20.18 ; 50.8 ; 50.18 ; \\
80.42 ; 80.46] \\
\text { [Search/exploration: } 20.15 ; 50.29 ; 80.40]\end{array}$ \\
\hline
\end{tabular}


Table 7. Mapping themes in 20-factor analysis to themes in 50- and 80-factor analyses.

\begin{tabular}{|c|c|c|}
\hline F20 & Themes & 20+ - Mapping with 50-Factor and 80-Factor Terms \\
\hline F20.1 & $\begin{array}{l}\text { Context and fixation in } \\
\text { ill-defined problems }\end{array}$ & $\begin{array}{l}\text { [Ill-defined problems/solutions: 50.1; 80.69; 80.70] } \\
\text { [Fixation: 80.15; 80.43; 80.77] } \\
\text { [Context: 50.7; 50.18;80.6;80.21;80.30;80.78] }\end{array}$ \\
\hline F20.2 & $\begin{array}{l}\text { Mastery and breadth of } \\
\text { skills }\end{array}$ & $\begin{array}{c}\text { [Mastery: } 50.2 ; 50.47 ; 80.2 ; 80.22 ; 80.24 ; 80.26] \\
\text { [Knowledge/skills: } 50.17 ; 80.4 ; 80.14 ; 80.16 ; 80.21 ; 80.45 ; 80.49 ; 80.52 ; \\
80.57 ; 80.59 ; 80.76 ; 80.77]\end{array}$ \\
\hline F20.3 & $\begin{array}{l}\text { Collaboration } \\
\text { experience }\end{array}$ & $\begin{array}{c}\text { [Participation/involvement/engagement/collaboration: 50.22; 80.1; 80.12; } \\
\text { 80.50;80.62; 80.66] } \\
\text { [Experience:80.22; 80.50; 80.51;80.75;80.66] }\end{array}$ \\
\hline F20.4 & $\begin{array}{l}\text { Interaction and } \\
\text { solution focus }\end{array}$ & $\begin{array}{l}\text { [Interaction/Iterate: } 50.8 ; 50.3 ; 50.33 ; 50.36 ; 80.7 ; 80.24 ; 80.53 ; 80.63 ; 80.66 \text {; } \\
\quad 80.67] \\
\text { [Solution/alternative: } 50.41 ; 80.41 ; 80.43 ; 80.44 ; 80.70]\end{array}$ \\
\hline F20.5 & $\begin{array}{l}\text { Operations and design } \\
\text { process }\end{array}$ & $\begin{array}{l}\text { [Operations, techniques, methods, and tools: } 50.5 ; 50.6 ; 50.10 ; 50.23 ; \\
50.35 ; 50.20 ; 50.48 ; 80.5 ; 80.34 ; 80.58 ; 80.55] \\
\text { [Design process: } 50.19 ; 50.26]\end{array}$ \\
\hline F20.6 & $\begin{array}{l}\text { Efficiency in novel } \\
\text { concepts and solutions }\end{array}$ & $\begin{array}{c}\text { [Concept/idea: 50.8; 50.18;50.42; 80.8; 80.42; 80.46] } \\
\text { [Solution/alternative: } 50.41 ; 80.41 ; 80.43 ; 80.44 ; 80.70] \\
\text { [Creativity/innovation/novelty: 50.49;80.25;80.74;80.31;80.71] } \\
\text { [Effective/efficient: } 50.2 ; 50.4 ; 50.9 ; 50.19 ; 50.27 ; 80.47 ; 80.59 ; 80.9 ; 80.25]\end{array}$ \\
\hline F20.7 & $\begin{array}{l}\text { Individual and team } \\
\text { performance }\end{array}$ & $\begin{array}{l}\text { [Performance: } 50.19 ; 50.35 ; 50.37 ; 80.19 ; 80.31 ; 80.68] \\
\text { [Team: } 50.7 ; 50.37 ; 80.7 ; 80.54 ; 80.66 ; 80.68 ; 80.72]\end{array}$ \\
\hline F20.8 & Co-creation of concepts & $\begin{array}{c}\text { [Co-creation: } 50.13 ; 50.14 ; 50.22 ; 50.42] \\
\text { [Concept/idea: } 50.8 ; 50.18 ; 80.8 ; 80.42 ; 80.46]\end{array}$ \\
\hline F20.9 & $\begin{array}{l}\text { Assessment: } \\
\text { effectiveness and } \\
\text { efficiency }\end{array}$ & $\begin{array}{l}\text { [Assessment/evaluation/judgement: } 50.9 ; 50.16 ; 50.19 ; 50.36 ; 80.17 ; 80.32 \text {; } \\
\quad 80.36 \text { ] } \\
\text { [Effective/efficient: } 50.2 ; 50.4 ; 50.9 ; 50.19 ; 50.27 ; 80.47 ; 80.59 ; 80.9 ; 80.25 \text { ] }\end{array}$ \\
\hline F20.10 & Idea generation process & $\begin{array}{c}\text { [Concept/idea: } 50.8 ; 50.18 ; 50.42 ; 80.8 ; 80.42 ; 80.46 \text { ] } \\
\text { [Generation: } 80.44 ; 80.64 \text { ] }\end{array}$ \\
\hline F20.11 & $\begin{array}{l}\text { Forecasting by making } \\
\text { conjectures about ideas }\end{array}$ & $\begin{array}{l}\text { [Concept/idea: } 50.8 ; 50.18 ; 50.42 ; 80.8 ; 80.42 ; 80.46] \\
\text { [Reflective practice/conjectures: } 50.1 ; 50.10 ; 50.15 ; 50.21 ; 50.29 ; 80.8 ; \\
80.20 ; 80.56 ; 80.75]\end{array}$ \\
\hline F20.12 & $\begin{array}{l}\text { Managing uncertainty } \\
\text { and complexity }\end{array}$ & [Complexity: 50.12; 50.35; 80.35; 80.60] \\
\hline F20.13 & $\begin{array}{l}\text { Training and } \\
\text { experience }\end{array}$ & $\begin{array}{l}\text { [Training: } 50.13 ; 50.27 ; 80.50 ; 80.13 ; 80.51 ; 80.71] \\
\text { [Experience: } 80.22 ; 80.50 ; 80.51 ; 80.75]\end{array}$ \\
\hline F20.14 & Design management & [Management: 80.72] \\
\hline F20.15 & $\begin{array}{l}\text { Exploration and } \\
\text { analysis }\end{array}$ & $\begin{array}{l}\text { [Search/exploration: } 50.29 ; 80.40 \text { ] } \\
\text { [Analysis: 50.15;50.40;50.46; 80.15] }\end{array}$ \\
\hline F20.16 & $\begin{array}{l}\text { Idea and creativity } \\
\text { development }\end{array}$ & $\begin{array}{l}\text { [Concept/idea: } 50.8 ; 50.18 ; 50.42 ; 80.8 ; 80.42 ; 80.46] \\
\text { [Creativity/innovation/novelty: 50.49; 80.25;80.74; 80.31; 80.71] } \\
\text { [Development: } 50.17 ; 50.50 ; 80.16 ; 80.30 ; 80.38 ; 80.41]\end{array}$ \\
\hline F20.17 & $\begin{array}{l}\text { Design techniques and } \\
\text { methods }\end{array}$ & $\begin{array}{l}\text { [Operations, techniques, methods, and tools: } 50.5 ; 50.6 ; 50.10 ; 50.23 \text {; } \\
\qquad 50.35 ; 50.20 ; 50.48 ; 80.5 ; 80.34 ; 80.58 ; 80.55]\end{array}$ \\
\hline F20.18 & $\begin{array}{l}\text { Concepts and } \\
\text { knowledge-based } \\
\text { design }\end{array}$ & $\begin{array}{l}\text { [Concept/idea: } 50.8 ; 50.18 ; 50.42 ; 80.8 ; 80.42 ; 80.46] \\
\text { [Knowledge/skills: } 50.11 ; 50.17 ; 50.31 ; 50.33 ; 50.37 ; 50.39 ; 50.46 ; 80.4 ; \\
\text { 80.14; 80.16; 80.21; 80.45; 80.49;80.52; 80.57; 80.59; 80.76; 80.77] }\end{array}$ \\
\hline F20.19 & $\begin{array}{l}\text { Framing and assessing } \\
\text { design }\end{array}$ & $\begin{array}{c}\text { [Framing/structure: } 50.23 ; 50.31 ; 80.40] \\
\text { [Assessment/evaluation/judgement: } 50.9 ; 50.16 ; 50.19 ; 50.36 ; 80.17 ; 80.32 \text {; } \\
80.36 \text { ] }\end{array}$ \\
\hline F20.20 & $\begin{array}{l}\text { Assumptions and } \\
\text { design management }\end{array}$ & $\begin{array}{l}\text { [Reflective practice/conjectures/assumptions: } 50.1 ; 50.10 ; 50.15 ; 50.20 ; \\
50.21 ; 50.29 ; 80.8 ; 80.20 ; 80.56 ; 80.75 \text { ] [Management: } 80.72 \text { ] }\end{array}$ \\
\hline
\end{tabular}


In this regard, the mapping of a theme can be used to assess its breadth and dominance across the different factor analyses, as is covered in the design literature. Thus, themes identified in factors with low level of detail or that appeared in two or more consecutive factors, can be seen as having higher significance for design expertise than those that emerge once in factors with a high level of detail. For example, F12.12 'Design know-how and concept exploration' is a comprehensive theme covering notions such as knowledge, skills, and concepts and ideas, which are frequently referred to in the design expertise literature. This was reflected in the mapping established between this theme at the 12-factor analysis, and other themes identified across the 20-, 50-, and 80-factor analyses. Another example is F12.11 dealing with 'Reflective, participatory, and interactive approaches'. Since design is a practice-oriented discipline, several topics in the design expertise literature referred to the conduct or practices of the designers, as identified in theme F12.11. In contrast, other themes showed to be narrower and more specific. For example, F12.4 'Model based idea generation', F12.5 'Operations and tools', and F12.9 'Quality and assessment' had fewer mapping associations with the list of themes identified across the 20-, 50-, and 80-factor analyses. It is also important to note that themes emerging at certain level of analysis were not mutually exclusive, nor was the mapping across the different levels of analysis. That certain themes can appear more than one time at a certain level, as well as across several levels of analysis, reflected the subjectivity of the terms and concepts in the research on expertise in design.

The mapping of themes in 20-factor analysis with those in 50- and 80-factor analyses also revealed differences in breadth for each theme, as reflected in the design literature. For instance, themes such as 20.16 'Idea and creativity development' are rather broad and largely covered in design expertise literature. In contrast, themes such as F20.14 'Design Management' and F20.12 'Managing uncertainty and complexity' are more specific, and tend to be infrequent in the design literature. A reason that themes like these were not observed in factors with higher level abstractions (e.g., 12-factor analysis) is because they are not considered to be central to design expertise. Although the use of LSA in the present study provided preliminary insights into the main themes and patterns that emerged from existing literature, further qualitative research and expert feedback may reveal additional reasons for the observed themes and patterns.

\section{Implications for Design Training and Design Education}

With 'design thinking' gaining wider recognition as a mainstream 'critical thinking' approach across various industry sectors, there is an increasing demand for multi-disciplinary design knowledge, skills, and education. Thus, a better understanding of the patterns and trends associated with design expertise will be beneficial for students and teachers interested in design training and education. To this aim, findings from the present study revealed thematic patterns and factors associated with design expertise. Some of the identified themes and factors relate to what characterizes design expertise, whereas others are concerned with how design expertise is acquired. These factors are domain independent, and can be combined and applied to various disciplines where design education is encouraged.

A main contribution of this paper was to present a structured assessment that allowed identification of these factors at different levels of detail, ranging from 12 to 80 factors. The different levels of abstraction offer a convenient reference that can be used in support of pedagogical goals, and for planning training. For instance, general categories of 12-20 factors may be relevant for curriculum development tasks, and for intervention programs to define teaching objectives in design related courses. On the other hand, more detailed categories of 50-80 factors might be suitable for dealing with specific design problem-solving tasks.

Not only factors, but also the connections between factors and related themes can be used as guidelines and checklists for intervention programs in design training and education. It is likely that experienced design educators, expert practitioners and mentors, and well-planned design training programs already account for some or most of the identified factors. Even so, the present findings 
can be used as a general "route map" or "check-lists" to identify opportunities for improvement in educational environments such as the design studio.

\section{Future Work}

Further analysis of the main themes and contents in design expertise literature focusing on the chronology of studies, and the disciplinary background of key authors, will be carried out in a future study. It is possible that the journals considered in the literature review largely focus on design thinking. Additional studies should consider including other design sources that have an interest in the social context as well. An international survey on the perception of design expertise among students, academics, and professionals is currently underway, and the findings will be compared to a literature review. Such investigation will provide additional insights into the evolving pattern of major topics in design expertise through time, as well as into implications for design education.

Findings from this research, in particular the connections and links between factors and related themes, can be considered as a basis for developing an ontological framework aimed at representing 'Design Expertise' knowledge in information systems. Such a semantic representation-e.g., using the Resource Description Framework (RDF) schema [94]—can be useful for enhancing information management, as well as search and navigation of content related to design expertise. In order to implement the RDF representation, further iterations on the different labels and cross-factor linking will be required, including labeling of the relationships between the factors. A preliminary attempt was made to build an ontological framework of the 'DesignExpertiseFactors' using an RDF representation in Protégé, which is a work in progress. An XML output of the 'DesignExpertiseFact' can be accessed in [95].

\section{Conclusions}

With the increasing significance of design across different disciplines, there is a need to understand what the characteristics that define design expertise are, and the conditions that may foster the acquisition of design expertise. However, the broad corpus of existing literature makes its objective review an ambitious enterprise, particularly when it comes as an exhaustive manual process. It is often the case that the manual review approach is subjective and limiting in regard to the number of articles that can be covered, which are not always representative of the topic under consideration. Therefore, the main goals of this study were to understand what the major topics and trends related with design expertise in the current literature are, and to explore whether and how these can be organized and categorized into main thematic patterns.

This paper presented a systemic analysis and assessment of the thematic patterns in design expertise literature, primarily focusing on sources that publish articles from different design disciplines. This allowed gaining a comprehensive insight into design expertise with regard to main trends and topics. Congruence with the traditional literature review was found, suggesting that LSA can be considered as a promising complementary supporting tool. On the other hand, the analysis carried out by LSA also showed some differences with respect to the emerging categories. The patterns that turned up through the factor analysis indicated that the design expertise literature not only covers themes related to cognitive processes and cognitive studies on design expertise, but also managerial aspects of design expertise. That is, besides design problem solving skills and cognitive processes, other issues such as interaction, training, operationalization of tools and methods, quality, and assessment also showed to be concerned with design expertise. All these have important implications for design training and education.

Author Contributions: Conceptualization: H.C.; Methodology, V.S.; Software, V.S.; Validation, V.S. and H.C.; Formal Analysis, V.S.; Investigation, H.C. and V.S.; Resources: H.C. and V.S.; Data Curation: H.C. and V.S.; Writing - original draft preparation, H.C. and V.S.; Visualization, H.C and V.S.; Writing-review and editing, H.C.

Funding: This research received no external funding. 
Acknowledgments: Thanks are due to Mehmet Yalcinkaya for helping with the semantic analysis of the collected data.

Conflicts of Interest: The authors declare no conflict of interest.

\section{References}

1. Mieg, H.A. Two factors of expertise? Excellence and professionalism of environmental experts. High Abil. Stud. 2009, 20, 91-115. [CrossRef]

2. Dorst, K. On the problem of design problems-problem solving and design expertise. J. Des. Res. 2004, 4, 185-196. [CrossRef]

3. Cross, N. The nature and nurture of design ability. Des. Stud. 1990, 11, 127-140. [CrossRef]

4. Ericsson, K.A.; Lehmann, A.C. Expert and exceptional performance: Evidence of maximal adaptation to task constraints. Annu. Rev. Psychol. 1996, 47, 273-305. [CrossRef] [PubMed]

5. Chi, M.T.H.; Feltovich, P.J.; Glasser, R. Categorization and representation of physics problems by experts and novices. Cogn. Sci. 1981, 5, 121-152. [CrossRef]

6. Hsu, Y.-S.; Lin, L.-F.; Wu, H.-K.; Lee, D.-Y.; Wang, F.-K. A novice-expert study of modeling skills and knowledge structures about air quality. J. Sci. Educ. Technol. 2012, 21, 588-606. [CrossRef]

7. Landauer, T.K.; McNamara, D.S.; Dennis, S.; Kintsch, W. Handbook of Latent Semantic Analysis; Lawrence Erlbau: Mahwah, NJ, USA, 2007.

8. Sidorova, A.; Evangelopoulos, N.; Valacich, J.S.; Ramakrishnan, T. Uncovering the intellectual core of the information systems discipline. Manag. Inf. Syst. Q. 2008, 32, 467-482. [CrossRef]

9. Yalcinkaya, M.; Singh, V. Patterns and trends in Building Information Modeling (BIM) research: A latent semantic analysis. Autom. Constr. 2015, 50, 58-80. [CrossRef]

10. Kundu, A.; Jain, V.; Kumar, S.; Chandra, C. A journey from normative to behavioral operations in supply chain management: A review using Latent Semantic Analysis. Expert Syst. Appl. 2015, 42, 796-809. [CrossRef]

11. Achakulvisut, T.; Acuna, D.E.; Ruangrong, T.; Kording, K. Science Concierge: A Fast Content-Based Recommendation System for Scientific Publications. PLoS ONE 2016, 11, e0158423. [CrossRef] [PubMed]

12. Natale, F.; Fiore, G.; Hofherr, J. Mapping the research on aquaculture. A bibliometric analysis of aquaculture literature. Scientometrics 2012, 90, 983-999. [CrossRef]

13. Cross, N. Expertise in design: An overview. Des. Stud. 2004, 25, 427-441. [CrossRef]

14. Cross, N. Special issue on expertise in design. Des. Stud. 2004, 25, 425-545. [CrossRef]

15. Cross, N. Special issue on expertise in design. J. Des. Res. 2004, 4, 2.

16. Popovic, V. Expertise development in product design-Strategic and domain-specific knowledge connections. Des. Stud. 2004, 25, 527-545. [CrossRef]

17. Stanton, N.A.; Baber, C. Error by design: Methods for predicting device usability. Des. Stud. 2002, 23, 363-384. [CrossRef]

18. Atman, C.J.; Chimka, J.R.; Bursic, K.M.; Nachtman, H.L. A comparison of freshman and senior engineering design processes. Des. Stud. 1999, 20, 131-152. [CrossRef]

19. Björklund, T.A. Initial mental representations of design problems: Differences between experts and novices. Des. Stud. 2013, 34, 135-160. [CrossRef]

20. Alexander, P.A.; Judy, J.E. The interaction of domain specific knowledge in academic performance. Rev. Educ. Res. 1988, 4, 375-404. [CrossRef]

21. Cross, N. Design cognition: Results from protocol and other empirical studies of design activity. In Design Knowing and Learning: Cognition in Design Education; Eastman, C., Newstetter, W., McCracken, M., Eds.; Elsevier: Oxford, UK, 2001; pp. 79-103.

22. Lawson, B. Design in Mind; Butterworth-Heinemann: Oxford, UK, 1994.

23. Nagai, Y.; Taura, T.; Mukai, F. Concept blending and dissimilarity: Factors for creative concept generation process. Des. Stud. 2009, 30, 648-675. [CrossRef]

24. Chan, J.; Dow, S.P.; Schunn, C.D. Do the best design ideas (really) come from conceptually distant sources of inspiration? Des. Stud. 2015, 36, 31-58. [CrossRef]

25. Akin, O.; Akin, C. Frames of reference in architectural design: Analyzing the hyper-acclamation (A-h-a-!). Des. Stud. 1998, 17, 341-361. [CrossRef] 
26. Curry, T. A theoretical basis for recommending the use of design methodologies as teaching strategies in the design studio. Des. Stud. 2014, 35, 632-646. [CrossRef]

27. Akin, O. Necessary conditions for design expertise and creativity. Des. Stud. 1990, 11, 107-113. [CrossRef]

28. Lee, G.; Eastman, C.M.; Zimring, C. Avoiding design errors: A case study of redesigning an architectural studio. Des. Stud. 2003, 24, 411-435. [CrossRef]

29. Ball, L.J.; Ormerod, T.C. Structured and opportunistic processing in design: A critical discussion. Int. J. Hum. Comput. Stud. 1995, 43, 131-151. [CrossRef]

30. Yilmaz, Z.; Seifert, C. Creativity through design heuristics: A case study of expert product design. Des. Stud. 2011, 32, 384-415. [CrossRef]

31. Yilmaz, Z.; Daly, S.R.; Seifert, C.M.; Gonzalez, R. Evidence-based design heuristics for idea generation. Des. Stud. 2016, 46, 95-124. [CrossRef]

32. Ho, C. Some phenomena of problem decomposition strategy for design thinking: Differences between novices and experts. Des. Stud. 2001, 22, 27-45. [CrossRef]

33. Davies, S.P.; Castel, A.M. Contextualising design: Narratives and rationalisation in empirical studies of software design. Des. Stud. 1992, 13, 379-392. [CrossRef]

34. Liikkanen, L.A.; Perttula, M. Exploring problem decomposition in conceptual design among novice designers. Des. Stud. 2009, 30, 38-59. [CrossRef]

35. Ahmed, S.; Wallace, K.M.; Blessing, L.T.M. Understanding the differences between how novice and experienced designers approach Des. tasks. Res. Eng. Des. 2003, 14, 1-11. [CrossRef]

36. Ball, L.J.; Onarheim, B.; Christensen, B.T. Design requirements, epistemic uncertainty and solution development strategies in software design. Des. Stud. 2010, 31, 567-589. [CrossRef]

37. McComb, C.; Cagan, J.; Kotovsky, K. Lifting the veil: Drawing insights about design teams from a cognitively-inspired computational model. Des. Stud. 2015, 40, 119-142. [CrossRef]

38. Petre, M. How expert engineering teams use disciplines of innovation. Des. Stud. 2004, 25, 477-493. [CrossRef]

39. Goldschmidt, G. Avoiding design fixation: Transformation and abstraction in mapping from source to target. J. Creat. Behav. 2011, 45, 92-100. [CrossRef]

40. Goldschmidt, G. Visual displays for design: Imagery, analogy and databases of visual images. In Visual Databases in Architecture: Recent Advances in Design and Decision-Making; Koutamanis, A., Timmermans, H., Vermeulen, I., Eds.; Avebury: Aldershot, UK, 1995; pp. 53-76.

41. Krugger, C.; Cross, N. Solution driven versus problem driven design: Strategies and outcomes. Des. Stud. 2006, 27, 527-548. [CrossRef]

42. Casakin, H.; Ball, L.; Christensen, B.; Badke-Schaub, P. How do analogizing and mental simulation influence team dynamics in innovative product design? AIEDAM Artif. Intell. Eng. Des. Anal. Manuf. 2015, 29, 173-183. [CrossRef]

43. Casakin, H.; Goldschmidt, G. Expertise and the visual use of analogy: Implications for design education. Des. Stud. 1999, 20, 153-175. [CrossRef]

44. Casakin, H. Visual analogy, visual displays, and the nature of design problems: The effect of expertise. Environ. Plan. B Plan. Des. 2010, 37, 170-188. [CrossRef]

45. Casakin, H. Visual analogy as a cognitive stimulator for idea generation in design problem solving. In The Psychology of Problem Solving: An Interdisciplinary Approach; Helie, S., Ed.; Nova Science Publishers: New York, NY, USA, 2012.

46. Ball, L.J.; Ormerod, T.C.; Morley, N.J. Spontaneous analogising in engineering design: A comparative analysis of experts and novices. Des. Stud. 2004, 25, 495-508. [CrossRef]

47. Chai, C.; Cen, F.; Ruan, W. Behavioral analysis of analogical reasoning in design: Differences among designers with different expertise levels. Des. Stud. 2015, 36, 3-30. [CrossRef]

48. Meier, D.K.; Reinhard, K.J.; Carter, D.O.; Brooks, D.W. Simulations with elaborated worked example modeling: Beneficial effects on schema acquisition. J. Sci. Educ. Technol. 2008, 17, 262-273. [CrossRef]

49. Anderson, J.R. Cognitive Psychology and Its Implications, 4th ed.; W.H. Freeman: New York, NY, USA, 1995.

50. Casakin, H. Visual analogy as a cognitive strategy in the design process: Expert versus novice performance. J. Des. Res. 2004, 4, 124. [CrossRef]

51. Lawson, B. Schemata, gambits and precedent: Some factors in design expertise. Des. Stud. 2004, 25, 443-457. [CrossRef] 
52. Goldschmidt, G. Creative architectural design: Reference versus precedence. J. Archit. Plan. Res. 1998, 15, 258-270.

53. Lawson, B.; Dorst, K. Design Expertise; Architectural Press: London, UK, 2009.

54. Christiaans, H.; van Andel, J. The effects of examples on the use of knowledge in a student design activity: The case of the 'flying Dutchman'. Des. Stud. 1993, 14, 58-74. [CrossRef]

55. Casakin, H.; Badke-Schaub, P. Sharedness of team models in the course of design-related interactions between architects and clients. Des. Stud. 2017, 3, e14. [CrossRef]

56. Luck, R. Kinds of seeing and spatial reasoning: Examining user participation at an architectural design event. Des. Stud. 2012, 33, 557-588. [CrossRef]

57. Bernal, M.; Haymaker, J.R.; Eastman, C. On the role of computational support for designers in action. Des. Stud. 2015, 41, 163-182. [CrossRef]

58. Ball, L.J.; Evans, J.S.B.T.; Dennis, I.; Ormerod, T.C. Problem-solving strategies and expertise in engineering design. Think. Reason. 1997, 3, 247-270. [CrossRef]

59. Guindon, R. Designing the design process: Exploiting opportunistic thoughts. Hum. Comput. Interact. 1990, 5, 305-344. [CrossRef]

60. Bender, B.; Blessing, L.T.M. Re-Interpretation of conceptualization: A contribution to the advance of design theory. In Human Behaviour in Design: Individuals, Teams, Tools; Lindemann, U., Ed.; Springer: Berlin/Heidelberg, Germany, 2003; pp. 10-25.

61. Gobet, F. Expertise vs. talent. Talent. Dev. Excell. 2013, 75, 75-86.

62. Flager, F.; Gerber, D.J.; Kallman, B. Measuring the impact of scale and coupling on solution quality for building design problems. Des. Stud. 2014, 36, 180-199. [CrossRef]

63. Kim, J.; Ryu, H. A design thinking rationality framework: Framing and solving design problems in early concept generation. Hum. Comput. Interact. 2014, 29, 516-553. [CrossRef]

64. Dabbeeru, M.M.; Mukerjee, A. Discovering implicit constraints in design. In Design Computing and Cognition'08; Gero, J.S., Goel, A.K., Eds.; Springer Science Business Media B.V.: Berlin, Germany, 2008; pp. 201-220.

65. Cross, N. The expertise of exceptional designers. In Expertise in Design Creativity and Cognition; Cross, N., Edmonds, E., Eds.; Sydney University of Technology Press: Sydney, Australia, 2003; pp. 23-35.

66. Restrepo, J.; Christiaans, H. Problem structuring and information access in design. In Expertise in Design Creativity and Cognition; Cross, N., Edmonds, E., Eds.; Sydney University of Technology Press: Sydney, Australia, 2003; pp. 149-162.

67. Purcell, A.T.; Gero, J.S. The effects of examples on the results of a design activity. In Artificial Intelligence in Design' 91; Gero, J.S., Ed.; Butterworth-Heinemann: Oxford, UK, 1991; pp. 525-542.

68. Kokotovitch, V.; Purcell, T. Mental synthesis and creativity in design: An experimental examination. Des. Stud. 2000, 21, 437-449. [CrossRef]

69. Doboli, A.; Umbarkar, A. The role of precedents in increasing creativity during iterative design of electronic embedded systems. Des. Stud. 2014, 35, 298-326. [CrossRef]

70. Seitamaa-Hakkarainen, P.; Hakkarainen, K. Construction and composition in experts' and novices' weaving design. Des. Stud. 2001, 22, 44-66. [CrossRef]

71. Goncalves, M.; Cardoso, C.; Badke-Schaub, P. What inspires designers? Preferences on inspirational approaches during idea generation. Des. Stud. 2014, 35, 29-53. [CrossRef]

72. Kim, M.H.; Kim, Y.S.; Lee, H.S.; Park, J.A. An underlying cognitive aspect of design creativity: Limited commitment mode control strategy. Des. Stud. 2007, 28, 585-604. [CrossRef]

73. Kokotovitch, V. Problem analysis and thinking tools: An empirical study of non-hierarchical mind mapping. Des. Stud. 2008, 29, 49-69. [CrossRef]

74. Purcell, A.T.; Gero, J.S. Design and other types of fixation. Des. Stud. 1996, 17, 363-383. [CrossRef]

75. Vasconcelos, L.A.; Crilly, N. Inspiration and fixation: Questions, methods, findings, and challenges. Des. Stud. 2016, 42, 1-32. [CrossRef]

76. Crilly, N. Fixation and creativity in concept development: The attitudes and practices of expert designers. Des. Stud. 2015, 38, 54-91. [CrossRef]

77. Sio, U.N.; Kotovsky, K.; Cagan, J. Fixation or inspiration? A meta-analytic review of the role of examples on design processes. Des. Stud. 2015, 39, 70-99. [CrossRef] 
78. Deerwester, S.C.; Dumais, S.T.; Landauer, T.K.; Furnas, G.W.; Harshman, R.A. Indexing by latent semantic analysis. J. Assoc. Inf. Sci. Technol. 1990, 41, 391-407. [CrossRef]

79. Han, J.; Kamber, M. Data Mining: Concepts and Techniques; Morgan Kaufmann Publishers: San Francisco, CA, USA, 2006.

80. Hossain, M.M.; Prybutok, V.; Evangelopoulos, N. Causal latent semantic analysis (cLSA): An Illustration. Int. Bus. Res. 2011, 4, 38. [CrossRef]

81. Delen, D.; Crossland, M. Seeding the survey and analysis of research literature with text mining. Expert Syst. Appl. 2008, 34, 1707-1720. [CrossRef]

82. Griffiths, T.L.; Steyvers, M. Finding Scientific Topics. In Proceedings of the National Academy of Sciences: Mapping Knowledge Domains, Irvine, CA, USA, 9-11 May 2004; Volume 101, pp. 5228-5235.

83. Husbands, P.; Simon, H.; Ding, C.H. On the use of the singular value decomposition for text retrieval. Comput. Inf. Retr. 2001, 5, 145-156.

84. Salton, G.; Buckley, C. Term-weighting approaches in automatic text retrieval. Inf. Process. Manag. 1988, 24, 513-523. [CrossRef]

85. Manning, C.D.; Raghavan, P.; Schütze, H. Introduction to Information Retrieval; Cambridge University Press: Cambridge, UK, 2008.

86. Abdi, H. Multivariate analysis. In Encyclopedia of Social Sciences Research Methods; Lewis-Beck, M., Bryman, A., Futing, T., Eds.; Sage: Thousand Oaks, CA, USA, 2003.

87. Dominowski, R. Productive problem solving. In The Creative Cognition Approach; Finke, R., Ward, T., Smith, S., Eds.; MIT Press: Cambridge, UK, 1995; pp. 73-95.

88. Macmillan, S. Added value of good design. Build. Res. Inf. 2007, 34, 257-271. [CrossRef]

89. Juran, J.M.; Godfrey, A.B. JURAN'S Quality Handbook, 5th ed.; McGraw-Hill: New York, NY, USA, 1999.

90. Johnson, K. The general study of expertise. In Expertise in Second Language Learning and Teaching; Johnson, K., Ed.; Palgrave Macmillan: New York, NY, USA, 2005; pp. 11-33.

91. Schön, D.A. The Reflective Practitioner: How Professionals Think in Action; Temple Smith: London, UK, 1983.

92. Schön, D.A. Designing as reflective conversation with the materials of a design situation. Knowl. Based Syst. 1992, 5, 3-14. [CrossRef]

93. Cannon-Bowers, J.A.; Salas, E.; Converse, S. Shared mental models in expert team decision making. In Individual and Group Decision Making: Current Issues; Castellan, N.J., Jr., Ed.; Lawrence Erlbaum: Hillsdale, MI, USA, 1993; pp. 221-246.

94. Decker, S.; Melnik, S.; van Harmelen, F.; Fensel, D.; Klein, M.; Broekstra, J.; Erdmann, M.; Horrocks, I. The Semantic Web: The roles of XML and RDF. IEEE Internet Comput. 2000, 4, 63-73. [CrossRef]

95. GitHub. DesignExpertiseFactors-Preliminary ontological framework. Available online: https://github. com/weshallsing/newRep/blob/17f925e7295bddaa1223b3402f4fa4edff574fec/DesignExpertiseFact.owl.xml (accessed on 2 August 2019). 